\title{
Exploring Strategies Microenterprise Owners use to Succeed in Business Beyond 2 Years
}

Tamika Ebony Haynes*

College of Management and Technology, Walden University, USA

\begin{abstract}
In the United States, microenterprises, critical segment of the small business population, accounts for 110 million small businesses that source new jobs. Despite the increase in the number of created businesses in the USA, more than $70 \%$ of microenterprise business owners are unsuccessful after 2 years. The multiple case study included 6 participants living in Houston, Texas, and intended to explore business strategies microenterprise event management owners used to succeed in business beyond 2 years. The conceptual framework that grounded the study was the 5-stage small business growth model and the 5-stage of the evolution of entrepreneurship theory. The data collection process consisted of interviews resulting in transcripts, review of company documents, and interview observations notes. The data analysis process while triangulating the data consisted of creating thematic codes, and clustering keywords, and ideas from the data. Development of visual aids assisted with organizing information, synthesizing, and generating new ideas. Text, word, and matrix coding queries were conducted and summarized for a cross-case analysis as relating to the interview questions. Thematic analysis and cross-case analysis revealed 3 major themes: customer relationship management, education/work experience, and promotional activities. Implications for social change include encouraging entrepreneurial and small business development programs to develop innovative curriculums that microenterprise business owners may benefit from to increase more business opportunities. An increase in microenterprises may help provide more employment opportunities that meet the needs of local communities and improve socioeconomic conditions.
\end{abstract}

Keywords: Microenterprise; Business; Exploring strategies

\section{Introduction}

More than 110 million microenterprises and small businesses are the source of all new jobs in the United States [1-3]. A largest percentage of new jobs in the USA are the direct result of microenterprises with few or no employees by owner managed and operated businesses [4]. Fifty percent of small and medium businesses survive beyond the first 5 years $[4,5]$. Within the United States, the failure rate is high, with $70 \%$ of these businesses failing after 2 years of operation [5]. The high failure rate affects the number of available employment opportunities in the United States [6]. In this multiple case study, I explored the strategies used by one sector of microenterprises and small business event management owners to succeed in business beyond 2 years.

\section{Background}

Microenterprises and small businesses represent $99 \%$ of the workforce population in the U.S. [7]. Although small businesses have been recognized for their contributions to economic growth, only $70 \%$ remain in business after 2 years (SBA, 2014) [4]. The reasons why scholars suggested that business owners do not persist after 2 years contributes to several factors not limited to lack of skill set with financial management $[5,8]$. Other scholars have suggested the lack of marketing knowledge [9], little to no formal and informal business networks [10], planning [11], business experience, and skills [12]. As a result, of the alarming high business failure rates in the U.S. research on small business development has emerged.

Scholars have suggested insufficient financial management [8], human capital/skill, education and knowledge base [6], social capital/ networking [13], and lack of transferable industry experience and skills [12] are factors associated with why some business owners fail within 2-years. Others have attributed planning [11], timing and mode of entry [8], marketing [9], industry competitive culture awareness [14], and preparation for growth [15]. The lack of varying insight into what strategies are successful may negatively impact the owners' ability to continue their operations beyond 2 years. Despite points of agreement, improvements in the U.S. economic growth increases when business owners implement successful strategies [11].

\section{Research question}

The research question addressed in this study is as follows: What strategies did microenterprise, event management owners use to succeed in business beyond 2 years?

\section{Research Methodology}

I incorporated qualitative methodology because the strategy (a) results in themes from the data, and (b) the problem requires an explanation beyond a yes or no answer. The qualitative methodology was flexible. Additionally, researchers can integrate unforeseen findings while having sufficient time to collect detail data from each participant [16].

\section{Conceptual framework}

I used two conceptual frameworks to support this study. The first conceptual framework presented was the organizational life cycle (OLC) [17]. Tenets in the early to mid-1900s of the model vary. Churchill and

${ }^{*}$ Corresponding author: Tamika Ebony Haynes, College of Management and Technology, Walden University, USA, Tel: 12813156053; E-mail: drtammyhaynes@gmail.com

Received January 12, 2018; Accepted January 24, 2018; Published February 02,2018

Citation: Haynes TE (2018) Exploring Strategies Microenterprise Owners use to Succeed in Business Beyond 2 Years. J Bus Fin Aff 7: 312. doi: 10.4172/21670234.1000312

Copyright: (c) 2018 Haynes TE. This is an open-access article distributed under the terms of the Creative Commons Attribution License, which permits unrestricted use, distribution, and reproduction in any medium, provided the original author and source are credited. 
Lewis [17] are the most prominent tenets of the OLC model. The key concepts of the model have common themes contributed to changes in business transitional patterns [18]. Scholars use the OLC model to illustrate predictable transitional patterns, common problems, and key strategies necessary for growth as a business transitions through the stages of a life cycle [18]. The 3- stages of the life cycle include (a) existence, (b) survival, and (c) success-growth.

The second conceptual framework I used is the 5-stage evolution of entrepreneurship theory. Arenius and Ehrstedt developed the theory in 2008 [19]. The key concepts of the theory illustrate the trial and error process involved in an entrepreneur's transition into being a self-employed business owner [19]. Researchers use the evolution of entrepreneurship theory to illustrate a relationship between a business owners' skill set and competitiveness and business survival $[8,20]$. The theory includes the following phases: (a) conception, (b) gestation, (c) birth, (d) infancy, and (e) adolescence.

I integrated both frameworks together to form the review of the professional and academic literature outline in this study. Both conceptual frameworks were suitable for the study because little research exist that recognize the stages of a life cycle in a small business prior to establishing key strategies for long-term success. As a result, the frameworks may aid nascent entrepreneurs and small business owners in identifying successful strategies at critical transitional phases necessary for keeping their business viable beyond 2 years.

\section{Five Key Stages of the Evolution of Entrepreneurialism in Small Business}

I focused the literature review on the first 3- stages of the 5-stages of small business growth model and supported by the components of the evolution of entrepreneurism theory. Arenius and Ehrstedt's [19] evolution of entrepreneurism theory in small business explored small business transitional stages. The 5-stages of the evolution of entrepreneurism theory listed by Arenius and Ehrstedt $[19,20]$ include conception, nascent/gestation, birth, infancy, and adolescence.

\section{Stage 1a: Existence (conception phase)}

Over 1,500 new microenterprises start every day in the United States [21]. According to Miettinen and Littunen [6], despite the intentions of positive business survival outcomes, several entrepreneurs fail in creating a lasting business. To enhance the likelihood of entrepreneurs surviving through the entrepreneurial process onto maturity, exploring the cognitive state of a potential entrepreneur during the initial conception stage prior to starting a business is critical.

The individual entering the stage of conception has made a conscious decision to change their professional status [22]. Klonek et al. [22] used a sample of 820 graduate students from two Universities in Germany. Klonek et al. established five discrete stages that an entrepreneur undergoes prior to adopting behaviors that lead to a prospective career option [22]. Klonek et al. depicted the conception stage introduced by Arenius and Ehrstedt as an attitudinal and cognitive state of mind only because the potential entrepreneur has not initiated any actions toward the activities of entrepreneurship [19,22]. The conception stage of the entrepreneurial process is a decisional balance that stimulated both by internal and external factors [22]. For different reasons, people reside in the pre-contemplation stage over a period because of ambiguity, or lack of intentions to pursue entrepreneurship as a career. On the other hand, other potential entrepreneurs enter the preparation stage immediately after conception and begin the process of evaluating and weighing the cost and benefits associated with starting a new venture
[22]. As some individual progresses toward the second stage, the pros begin to outweigh the cons.

Arenius and Ehrstedt [19] explored data from the 2005 Global Entrepreneurship Monitoring of potential entrepreneurs, baby business owners and seasoned entrepreneurs throughout 35 different countries. The transition between stages of the evolutionary entrepreneurial process is progressive over time [19]. In addition, an individual making the cognitive decision during the conception stage evolves over time into pursuits of entrepreneurship as a career. The first phase known as the conception stage of the entrepreneurial process is a collective view that includes all individuals in the workforce. Like previous research Arenius and Ehrstedt [19] extended the perspective of the conception stage, by suggesting that self-confident individuals who identified themselves as having the necessary entrepreneurial expertise to operate a business successfully were likely to engage in entrepreneurial activities. If entrepreneurial start-ups are the major drivers of wealth creation, job opportunities, and economic stabilization, examining the necessary attributes of potential entrepreneurs prior to entering the entrepreneurial start-up process is critical. Exploration of individual perceptions into entrepreneurship and small business will follow to help aid the researcher in the understanding of what strategies are important for small business success.

Entrepreneurial perception and decision drivers. Scholars suggested that the perception related to achievement needs within the life of entrepreneurs is often compelled by success [23]. Entrepreneurs pursue the decision to launch and operate new businesses for different reasons. Among the desire to own a business, entrepreneurs have varying initial perceptions prior to entry about personal drivers and motivations, skills and experience suitable enough to operate a business long term $[8,24]$. The entrepreneur's initial perceptions prior to entry influence not only the critical decision to pursue self-employment, or to seek other traditional employment opportunities, but motivate the start-up strategies implemented for the small business [24].

Scholars have explored and assessed cognitive structuring and the influences of judgment and decision making when assessing a new business venture opportunity $[25,26]$. New business ventures develop from personal ambiguity and often under uncertain conditions [27]. On one hand, individual mental model, values, norms, environment, and personal beliefs are primary contributors to the ideology of initializing a business idea [28]. Passion has been the primary motivation for individuals seeking to take over an established business or start a new one [27].

\section{Stage 1b: Existence (gestation phase)}

Despite the increase worldwide of individuals engaging in startup activities to start a new business, approximately $50 \%$ of small businesses fail at the gestation phase, within 2 years of initiation [29]. The gestation phase is a component of the initial existence stage. The existence phase is the beginning of the growth series of gestational phases in an OLC model. According to Arenius and Ehrstedt, during the gestation phase, individuals engage in activities aimed at launching a new firm are nascent entrepreneurs. An endless number of start-up activities exist after a nascent entrepreneur has entered the gestation stage of the business life cycle and engaged in actions associated with launching a new business.

Entrepreneurial mode of entry and timing: Despite the close attention from scholars and policy makers, little research exists on the factors that establish the mode of which individuals enter entrepreneurship [27]. While there is a significant lack of research on 
the topic [30], there are two primary theories on environmental and social economic constraints influencing an individual's entry mode into a business. The entry mode is one of the most critical phases of the start-up process and can establish a business for long-term survival and success. In contrast, choosing a mode of entry selection that is contradictive to an individual's skills, assets, knowledge, and experience can increase the probability of premature business failure [8].

The first and most critical strategy noted in the literature which entrepreneurs and business leaders use, is the mode of entry strategies $[27,28,31]$. The mode of entry into entrepreneurship can either be from an existing business, such as that of a family business or entrepreneurial franchise or the creation of a new business venture [27,31]. Parker and Van Pragg [27] used a cross-sectional sample of Dutch entrepreneurs residing in the Netherlands to analyze determinants that effect the individuals' decision on the entry into a business. Parker and Van Pragg argued the mode of entry by entrepreneurs have distinct differences between taking over a family business and establishing a new business. Specifically, Parker and Van Pragg [27] noted that individuals desiring to take over a family business required less formal education, transfer of tactical skills, and deployment of resources because of the dependence on the advance knowledge of their successors. The researchers implied that take over businesses required different human capital, then for individuals who desire to create a new business. While on the other hand, individuals with a higher education level had a higher probability of starting a new business even with the opportunity to reestablish a family business.

Bhat and Daulerio [31] explored determinant factors associated with social capital and financial capital on the selection of an individual mode of entry selection. Bhat and Daulerio [31] also explored determinants that influence an individual's decision to enter a new business or an already established business such as; industry experience, age, higher education, race, and hours worked per week. As a result, Bhat and Daulerio revealed that the modes of which some individual transitions into a business is contingent upon the sector of the business the individual selects.

\section{Stage 1c: Existence (birth phase)}

Approximately one out of every 10 adults have started a new business in the United States [32]. Despite the initiating actions of several entrepreneurs, 2-years after the conception of the venture countless businesses owners prematurely terminated the business. Churchill and Lewis [17] suggested business owners in the birth phase of the OLC are often young, flexible, unstructured, and informal in management styles. The birth phase is a component of the existence stage. Systems and formal planning in the existence stage are nonexistent. The primary objective of a business residing in the birth phase is to secure resources necessary to build and launch the basic business operations to ensure the business will survive [7].

Similarly, Arenius and Ehrstedt [19] acknowledged the birth stage as one of the most critical phases of the process because the individual's intents and actions become a reality that accumulates into a new firm. Activities after an individual has started a new business are countless. Furthermore, exploration of an approach to building a new team, in conjunction with various marketing tactics may add insight into what strategies are necessary for a small business to succeed [33].

Talent and acquisition: building a new venture team: Pressures of survival and establishing legitimacy in the market are just a few liabilities and challenges facing new microenterprises and small businesses in the United States [34,35]. As a result, new entrepreneurial ventures often launch through shared efforts, rather than solo proprietor selfemployed individuals alone [36]. Although, the topic of new venture team creation is relevant to the study research topic on successful strategies, however a considerable gap exists in the literature on the dynamics of entrepreneurial teams in relation to the organizational and corporate management teams.

Multiple definitions of venture team exist. However, the criteria of the study consist of a small number of like-minded members with shared commitments that work together to achieve a set of common goals for the sake of the growth and success of the business. The most critical trait of a venture team is the cohesive relationship among all members, and ultimately affects the overall growth and survival of a new business $[37,38]$. The recruitment process for new venture team members small business consist of base skill set and cohesive upon relationships. Although both are desirable, the dominate recruitment criteria for microenterprises and small business owners is team composition.

Cruz et al. [36] explored factors that influence team membership and formation among seven entrepreneurial family teams in Honduras. Cruz et al. [36] focused on larger and more diverse teams with different levels of commitment. Cruz et al. found the ambitions of younger team members within a family dynamic exceed the overall business objectives of successor members in the family. In addition, Cruz et al. [36] surmised the older generation level of commitment to the longterm involvement of the business was inevitable. As a result, Cruz et al. provided insight into the motivation of how entrepreneurship can maximize and provide quality stewardship of family wealth and well-being. However, Brannon et al. [39] researched the dynamics of teams for new ventures but focused on teams limited to two members. Venture teams regardless of maturity and size, are essential to the overall growth in a business [39]. Despite this, Schjoedt et al. surmised that family-based business teams often lack the skill set necessary to ensure new business success.

Marketing: An endless array of marketing strategies exists for both small, medium enterprise's, and larger corporations, many of which are developed and implemented based upon the entity's size, market position, age, and maturity of an organization $[9,40]$. Classic and generic marketing strategies could include anything from cost leadership, differentiation, and concentration to marketing segmentation, position, and mixes [9]. Having a variety of marketing strategies is more appropriate and is the primary focus of larger corporations, rather than small and medium-sized enterprises [1,33]. On the other hand, SME's tend to focus on niche strategy, horizontal integration, vertical integration, and co-competition strategy [9]. Marketing strategies are endless, and contingent upon the business size and maturity [33]. However, incorporating marketing strategies is a critical factor of business success especially during the early stages of development for small businesses [9].

The role of marketing within startup small businesses has gained significant attention within the research continuum over the past decades [9]. Consequently, Grissemann et al. [40] have found much conflict that exists with linking the role of strategic marketing management to business performance, and competitive advantage in different firms. Much of the literature on the role of strategic marketing in small businesses remains inconclusive $[9,33,40]$. Although countless small companies succeed past 5 years, the challenge remains for startup small businesses in the United States on the execution of how to attract and serve customers [5,9]. Cronin-Gilmore [2] and Grissemann et al. [40] agreed that small business performance is not contingent upon 
specific strategies, but rather upon the deployment of key resources to the most lucrative and earning potential targeted markets. In contrast, McKelvey [9] argued the literature does not show a positive link to the actual formation and development of a company's resources to an increase in business performance, especially for small businesses. Fiore et al. [7] conducted similar research and agreed that for small businesses to succeed marketing strategies need to extend beyond the limited resources that are available. Rather, the survival of a small business requires the owners to have internal complementary capabilities such as skills, knowledge acquired, combined with the resources in ways that imitate market conditions [8].

\section{Stage 2: Survival (infancy phase)}

Microenterprises and small businesses vary in size, structure, management style, the number of employees, and the capacity for growth [12]. Several business owners prematurely terminate their business just after two years. The early phase is a pivotal period in the life of the business process, as the challenge of growth both financially and managerial is now in existence. The infancy phase is a component of the survival stage. Churchill and Lewis acknowledged the business owner in a state of survival as a workable business entity. During the survival stage, Churchill and Lewis suggested the firm size rapidly increase as trained professionals now help oversee and share in the leadership and daily management of the business. Business owners often facilitate daily operations, even if other employees are present. Arenius and Ehrstedt [19] identified the business owners in the survival state as baby business owner who have now demonstrated to the market concrete legitimacy.

The duration period of the survival stage can vary from one business to the next. Baby business owners transition in and out of the OLC, and function in the baby business owner phase longer than others [41]. Arenius and Ehrstedt's [19] design reflects the baby business owner phase as requiring an establishment of different strategies. The infancy phase involves numerous themes, and not limited to the baby business owners having knowledge of the industry and competitive nature of industry of which the baby business owner expresses interest in to improve operational effectiveness [41].

\section{Stage 3: Success-growth (adolescences phase)}

If a venture owner can adapt to unpredictable environmental changes, and massive growth increases, the owner of the entrepreneurial business will achieve true economic health [15]. Successful businesses have become the central drivers of the United States economic recovery and growth [15]. On the other hand, the challenges faced during the adolescence stage are business operations that need to keep the company profitable and stable [19]. The adolescence phase is a component of the success-growth stage. Arenius and Ehrstedt [19] suggested the business owners in the success-growth stage have successfully navigated a new business from an elementary state into a more independent state of functioning that begins to access and fulfill the needs of the market consistently to maintain customers.

Churchill and Lewis [17] acknowledged the business owner in the success-growth stage as obtaining success through consistent growth. Often, the internal operations of a business in the success-growth stage are stable; and have established long-term planning, office systems, formal organizational structure, and consistent routines in its workplace. Churchill and Lewis [17], and Arenius and Ehrstedt [19] agreed that in the success-growth stage the development of the business is expanding rapidly, for which the business owner must prepare. If the business owner can implement key strategies to stabilize the business growth and navigate successfully through the self-regulated adolescence phase of the start-up process, the owner may disengage from the firm, placing the business under new management or ownership and launch additional ventures. Preparing for the challenges of growth while in the success-growth stage is critical to understanding what strategies are necessary for a small business to succeed.

\section{Presentation of the Findings}

The presentation of themes from the findings was supportive of the body of information represented in the 5-stage small business growth, the 5-stage evolution of entrepreneurship conceptual framework and the literature review. Three major themes support what strategies are necessary for an event management business owner to succeed beyond 2 years. All participants (100\%) in the study acknowledged that (a) customer relationship management, (b) education and work experience, and (c) promotional activities were key major strategies for successfully operating a microenterprise beyond 2 years. The findings showed proven strategies that business owners used to operate a business indefinitely, including insight on the best services to increase sales, profits, and market share.

\section{Major themes}

I used NVivo 11 pro, a computer software, to conduct thematic analysis, produce reports and charts, and to identify and analyze patterns in the data across cases. Figure 1 is a word cloud map developed from thematic synthesis from the analysis of all the data collected including participant interviews, personal journal notes from interview observations, and review of company documents.

The interviews were electronically transcribed using Transcribe $\mathrm{Me}$ online software. The transcribed interview data was uploaded, along with company documents, and notes from participants' observations into NVivo 11 pro, a qualitative data organization software tool. A node/ theme was assigned to each participant's response relevant to the research question. Table 1 reflects major themes that emerged from the analysis of the participant interviews, personal journal notes from interview observations and review of company documents. The three themes are in ascending order with the highest references from all sources collected.

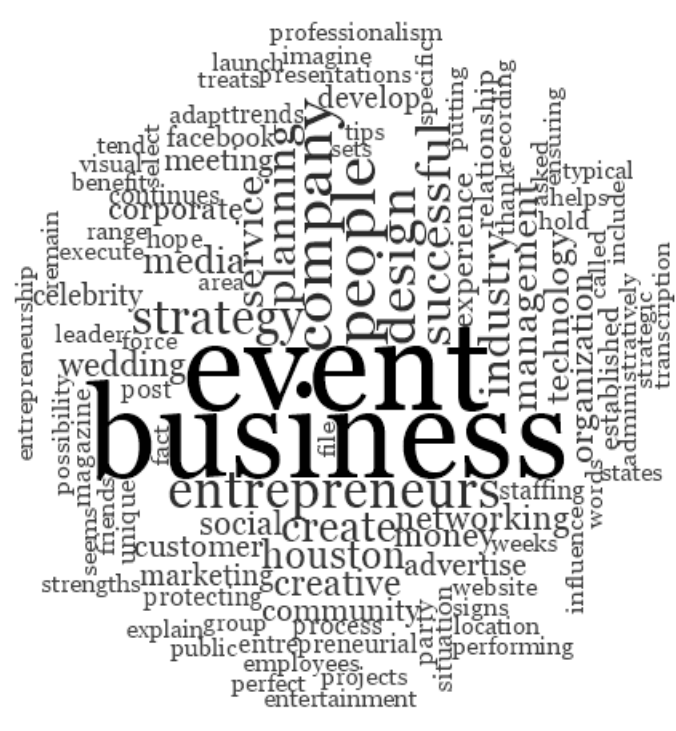

Figure 1: Word cloud map. 


\begin{tabular}{|l|c|c|}
\hline \multicolumn{1}{|c|}{ Themes } & Source & References \\
\hline Customer Relationship Management & 32 & 105 \\
\hline Education and Work Experience & 26 & 67 \\
\hline Promotional Activities & 26 & 65 \\
\hline
\end{tabular}

Table 1: List of Major Themes.

Theme 1: Customer relationship management: The first theme to emerge from participants who offered insight into the strategies used that are necessary to succeed beyond 2 years emphasized the concept of customer relationship management. The theme customer relationship management emerged as a theme specifically from responses to Interview Questions 1, 2, 3, 4, and 5. The findings from the study confirmed customer relationship management is a key factor in operating a viable business beyond 2 years. One hundred percent of the participants indicated that the event industry is a people based profession and managing customer relationship is an important strategy in the event management industry. Management of customer relationships varies between multiple groups, whether between family or friends, or a more formal network consisting of relationships with vendors, banks, accountants, creditors, venture capitalists, lawyers, and any trade officials. The customer relationship management theme supports Bastié et al. [10] and Rahman et al. [13] positive link between managing business relationships and staying viable as a business owner.

EMBO1, EMBO2, EMBO3, EMBO4, EMBO5, and EMBO6 all indicated that management of customers' relationships, whether the pursuit of a new relationship or maintaining an established relationship, impacts future business opportunities and is a critical strategy needed to start and grow a business long term. Bastié et al. [10] noted that entrepreneurs use close relationships they have established with their customer base to gather information to identify new and existing business opportunities. EMBO1, EMBO 2, and EMBO5 had the highest frequency of customer relationship management occurrences out of all the participants' responses. EMBO1, EMBO2, and EMBO5 all stated that the event industry is a visual type of business and that new business is contingent upon the success of whether you execute the clients' ideas, can verbally communicate the event vision, acquire, and implement feedback obtained successfully.

I discovered the theme customer relationship management as an effective strategy as the result of the responses from EMBO1, EMBO4, EMBO5, and EMBO6 which indicated that the only way to execute a client's event successfully was to first establish a consistent relationship. Understanding and taking out the time to get to know the customer has been a critical element to maintaining the same clientele and the initiation of new clients throughout their tenure as a business owner (EMBO1, EMBO4, EMBO5, and EMBO6). EMBO2 stated that they have been successful for so long due to the client-centered theme based philosophy implemented within their business. EMBO1 indicated that they rely on their management of customer relationships, ongoing communication, listening to the customers' needs, and including the customer in the decision-making process. All which are core values in their business and is how they obtain $85 \%$ of their customers. EMBO4 specifically developed a two-fold customer based management approach. The first implementation of this strategy was the direct result of the participant's (EMBO4) decrease in profit margins and volume sales. As a result, EMBO4 stated that they identify what other successful business owners have implemented and duplicated to be successful, then adopt the strategy based on their specialization and target customers. Table 2 represents the aggregated findings of a text content narrowed to reflect the references and frequency of the major theme customer relationship management. The references and frequency are patterns identified and developed from the collected data. Using a text generalization query, Table 2 reflects a thematic synthesis of the importance of customer relationships management, as expressed by the study participants.

Theme 2: Education and work experience: The second theme to emerge from the data emphasized the participants' experience with education and work experience for successful event management business owners. Eighty percent of the participants emphasized the concept of education and previous work experience as crucial to longterm success of an event management business owner. As a result, the findings from my study confirm education and work experience a key factor in operating a viable business beyond 2 years. My findings were supported by the works of Gudmundsson and Lechner, and Walker et al. [42] who asserted that education and work experience are pivotal fundamental elements to success, and evident as a common factor omitted among small businesses that have failed. The theme education and work experience emerged as a theme specifically from responses to Interview Questions 1, 2, 4 and 5. EMBO1, EMBO2, EMBO4, and EMBO5 had the highest number of references throughout the data collected. The participants of the study agreed that education and work experience were essential to growing and operating a viable business long-term (EMBO1, EMBO2, EMBO4, EMBO5). Participant EMBO3 and $\mathrm{EMBO} 6$ mentioned the degree and certificates they obtained from various universities; however, they did not emphasize education and work experience as a major factor or strategy for long-term success. This finding is like information Chwolka and Raith [25] found on education and related work experience of which they stated was not robustly linked to business, but rather a detailed business plan.

EMBO1 an event business owner of 15 years had the highest reference and frequency among other participants. EMBO1 explained that success as an event management business owner is a direct result of corporate work experience with project management and communications, in addition to working as an intern with the Social Office at the White House. EMBO1 also contribute undergraduate coursework in economic, tourism administration, events and meeting management from an Ivy League University equipped her with the knowledge about business principles, fundamentals, and theories that would aid her success in the event industry as a business owner, and the lifecycle of her business. Furthermore, EMBO1 emphasized the importance of ongoing research and reading books relevant to a specific industry and business of interest, along with participating in in-person and online training courses were critical to maintaining a balance and viable business beyond 2 years.

EMBO2 indicated that having spending 7 years within a similar company prior to business ownership was the direct result of having a better understanding and successfully operating his business of 30 years. EMBO4 contributed education from an Ivy League University as leverage to obtaining business and overall success in the event industry. EMBO4 stated that an education from a prestigious Ivy League school allotted her a platform to access A-list/ high class and celebrity target population that typical event management business owners did not

\begin{tabular}{|l|c|c|}
\hline \multicolumn{1}{|c|}{ Source } & Reference & Frequency (\%) \\
\hline EMBO1, Interview Questions/Notes/Documents & 73 & 47.75 \\
\hline EMBO2, Interview Questions/Notes/Documents & 26 & 12.66 \\
\hline EMBO3, Interview Questions/Notes/Documents & 11 & 19.13 \\
\hline EMBO4, Interview Questions/Notes/Documents & 21 & 5.57 \\
\hline EMBO5, Interview Questions/Notes/Documents & 21 & 24.14 \\
\hline EMBO6, Interview Questions/Notes/Documents & 15 & 4.30 \\
\hline
\end{tabular}

Table 2: References and frequency of customer relationship management. 
have access to. Furthermore, EMBO4 mentioned that people were more prone to hire her because of her education from an Ivy League University. EMBO 5 noted that education and work experience is an important component to long-term business succeeds for industry professionals. However, EMBO5 emphasized that more importantly, credentials and degrees are not enough to sustain a clientele and attribute loyalty and customer relationship as the primary strategy to their business success. Table 3 represents the aggregated findings of the text content narrowed to reflect the references and frequency of the major theme, and customer relationship management. The references and frequency are patterns identified and developed from the collected data. Table 3 reflects a thematic synthesis of the importance of education and work experience using a text generalizations query as expressed by the study participants.

Theme 3: Promotional activities: The third major theme emphasized during participant interviews highlighted the concept of implementing a variation of both paid and unpaid promotional activities. Unpaid/earned public relations activities as mentioned by the participants in the study include free advertisement through (a) word of mouth, (b) social media, and a (c) business exchange system. Paid/ Purchased promotional activities consist of marketing strategy such as through an (a) website, (b) publications, (c) industry leader platforms and SEO, and (d) business branding. The promotional activities theme emerged as a topic specifically from responses to interview questions 1 , 2,4 and 6 . One hundred percent of the participants identified the use of either an unpaid or paid promotional activity as one of the most pivotal strategies in the success of an event industry professional (EMBO1, EMBO2, EMBO3, EMBO4, EMBO5, EMBO6). Both the paid and unpaid promotional activities emerged from interview question 1, 3, 5 , and 6 . As a result, the findings from my study confirm promotional activities as a key component in operating a viable business beyond 2 years. Additionally, the finding supports the literature on McKelvey (2016) who also found that incorporating marketing strategies is a critical factor in business success especially during the early stages of development for small businesses.

Unpaid/Earned Public Relations Promotional Activities. EMBO1, EMBO2, ЕМBO3, ЕМBO4, ЕМBO5, ЕMBO6 all agreed that utilizing unpaid promotional activities helped recruit new clients and establish long-term success. Marketing strategies are endless, and contingent upon the business size and maturity [33]. One-hundred percent of the participants noted that the event industry is a visual business and visual aids to display business goods and services are required. EMBO1, a business owner of 15 years mentioned that $85 \%$ of their marketing and promotional efforts are focused on utilizing social media and industry platforms and SEO such as TheKnot.com, Weddingwire.com, Snap Chat, Facebook and Pinterest.com to promote their business to their targeted market. EMBO1 also referenced utilizing various free opportunities that were available who offered synergistic goods and services, such as, bloggers, writers, magazines or websites, who needed content for small business owners to promote their business for free.

\begin{tabular}{|l|c|c|}
\hline Source & Reference & Frequency (\%) \\
\hline EMBO1, Interview Questions/Notes/Documents & 147 & 83.85 \\
\hline EMBO2, Interview Questions/Notes/Documents & 67 & 35.07 \\
\hline EMBO3, Interview Questions/Notes/Documents & 11 & 23.68 \\
\hline EMBO4, Interview Questions/Notes/Documents & 55 & 14.18 \\
\hline EMBO5, Interview Questions/Notes/Documents & 26 & 30.17 \\
\hline EMBO6, Interview Questions/Notes/Documents & 7 & 18.58 \\
\hline
\end{tabular}

Table 3: Reference and frequency of education and work experience.
$\mathrm{EMBO} 2$ indicated that a good website combined with a strategic social media plan is required in the event industry, however, building customer relationships was the key factor to their success, and a major part of their business model. EMBO5 stated that they spent a lot of money on boosting Facebook posting, but yielded little to no new business. EMBO1, EMBO2, EMBO3, EMBO4, and EMBO6 did not mention using an exchange of goods or services as a strategic plan to leverage new business. However, EMBO5 contributed word of mouth, and business exchange such as discounts on event services to clients in exchange for newspaper and magazine publication was key to their success. EMBO3 and EMBO6 did not mention advertisement through word of mouth as a key strategy to obtaining new business or success and focused their efforts on promotion through a website.

Paid/Purchased Promotional Activities. One-hundred percent of participants in the study referenced utilizing a combination of both paid and unpaid promotional activities (EMBO1, EMBO2, EMBO3, EMBO4, EMBO5, and EMBO6). Having a good website was noted as the principal promotional strategy to display and showcase services and goods to the public as a critical aspect to business success in the event industry (EMBO1, EMBO2, ЕMBO3, ЕMBO4, ЕMBO5, ЕMBO6). EMBO1 utilized both paid and unpaid promotional activities but stated that only $15 \%$ of her marketing plan is contributed to using branded items such as business cards, distributional items, and a wrapped car with logo to market and advertise the business. EMBO1 leveraged using some free and paid publications in high-end magazines, and industry related newspapers and magazines. However, EMBO1 noted that local high-end print magazines were not effective promotional activities for their company and did not render new business. EMBO3 stated that majority of their new business was rendered directly a good website; however, publications in industry related magazines were key to their success.

Table 4 represents the aggregated findings of the text compiled and synthesized to reflect narrowed and generalized references and frequency of the promotional activities theme. The references and frequency are patterns identified and developed from the collected data. Table 4 reflects a thematic synthesis of the importance of promotional activities using a text generalization query as expressed by the study participants.

\begin{tabular}{|c|c|c|}
\hline Source & Reference & Frequency (\%) \\
\hline EMBO2, Interview Questions/Notes/Documents & 97 & 49.43 \\
\hline EMBO3, Interview Questions/Notes/Documents & 16 & 35.85 \\
\hline EMBO4, Interview Questions/Notes/Documents & 89 & 25.47 \\
\hline EMBO5, Interview Questions/Notes/Documents & 44 & 44.99 \\
\hline EMBO6, Interview Questions/Notes/Documents & 11 & 32.80 \\
\hline
\end{tabular}

Table 4: Reference and frequency of promotional activities.

\section{Conclusion}

Microenterprise event management owners use customer relationship management, education and work experience, and promotional activities as a primary strategy to address some of the daily challenges in achieving the company overall goal and mission. The findings of this study indicate that event management microenterprise owners must implement these strategies throughout the lifecycle of their business to operate effectively within the event industry. Event management microenterprise owners in this study used the customer relationship management, education and work experience, and promotional activities strategy daily to manage the best services to increase sales, profits, and market shares. 
Citation: Haynes TE (2018) Exploring Strategies Microenterprise Owners use to Succeed in Business Beyond 2 Years. J Bus Fin Aff 7: 312 . doi: 10.4172/2167-0234.1000312

The findings from the study indicated microenterprise; event management owners also use innovative methods such as customer relationship management, education, and work experience, and promotional activities to meet the overall daily needs of the business. Considering, the challenges that microenterprises and small business entrepreneurs face in the $21^{\text {st }}$ century in America may provide insights into what factors aid in assisting aspiring business owners on how to sustain a business beyond the critical point of the lifecycle of the company.

\section{References}

1. Liao C, Hung J, Kao H, Wu C (2014) Marketing strategy model: A conceptual framework for micro-enterprises. Human Systems Management 33: 199-206.

2. Cronin-Gilmore $\mathrm{J}(2012)$ Exploring marketing strategies in small businesses. Journal of Marketing Development and Competitiveness 6: 96-107.

3. Gohmann SF, Fernandez JM (2014) Proprietorship and unemployment in the United States. Journal of Business Venturing 29: 289-309.

4. U.S. Small Business Administration [SBA] (2014) Table of small business size standards matched to North American industry classification system codes.

5. Sarasvathy SD, Dew N (2013) Without judgment: An empirically based entrepreneurial theory of the firm. Review of Austrian Economics 26: 277-296.

6. Miettinen M, Littunen $\mathrm{H}$ (2013) Factors contributing to the success of startup firms using two-point or multiple-point scale models. Entrepreneurship Research Journal 3: 449-481.

7. Fiore AM, Niehm LS, Hurst JL, Son J, Sadachar A (2013) Entrepreneuria marketing: Scale validation with small, independently-owned businesses. Journal of Marketing Development and Competitiveness 7: 63-86.

8. Haniff SM, Halim MA (2014) Marketing capabilities and performance of SMEs in food and beverages industry in Malaysia. International Journal of Academic Research 6: 187-195.

9. McKelvey B (2016) Complexity ingredients required for entrepreneurial success. Entrepreneurship Research Journal 6: 53-73.

10. Bastié F, Cieply S, Cussy P (2013) The entrepreneur's mode of entry: The effect of social and financial capital. Small Business Economics 40: 865-877.

11. Mitchelmore S, Rowley J (2013) Growth and planning strategies within womenled SMEs. Management Decision 51: 83-96.

12. Block JH, Kohn K, Miller D, Ullrich K (2015) Necessity entrepreneurship and competitive strategy. Small Business Economics 44: 37-54.

13. Rahman SA, Amran A, Ahmad NH, Taghizadeh SK (2015) Supporting entrepreneurial business success at the base of pyramid through entrepreneurial competencies. Management Decision 53: 1203-1223.

14. Dadzie CA, Winston EM, Dadzie KQ (2012) Organizational culture, competitive strategy, and performance in Ghana. Journal of African Business 13: 172-182.

15. McFarland C, McConnell JK (2013) Small business growth during a recession local policy implications. Economic Development Quarterly 27: 102-113.

16. Leedy PD, Ormrod JE (2013) Practical research: Planning design (10th edn.), Upper Saddle River, NJ: Pearson Education.

17. Churchill NC, Lewis VL (1983) The five stages of small business growth Harvard Business Review 61: 30-50.

18. Lipi R (2013) The growth performance of small business under the view of lifecycle model. Management Research and Practice 5: 58-67.

19. Arenius $P$, Ehrstedt $S$ (2008) Variation in the level of activity across the stages of the entrepreneurial startup process-evidence from 35 countries. Studies in Economics 35: 133-152.

20. Bygrave WD, Zacharakis A (2014) Entrepreneurship. (3rd edn.), Hoboken, NJ: Wiley Publisher.
21. Hamrouni A, Akkari I (2012) The entrepreneurial failure: Exploring links between the main causes of failure and the company life cycle. Internationa Journal of Business and Social Science 3: 189-205.

22. Klonek FE, Isidor R, Kauffeld S (2014) Different stages of entrepreneurship: lessons from the tran theoretical model of change. Journal of Change Management 15: 43-63.

23. Bembenek B, Piecuch T, Sudol-Pusz J (2016) Business clusters and socia cooperatives-a chance to promote female entrepreneurship in rural Poland? In: Women and Migration in Rural Europe. Palgrave Macmillan, UK, pp: 170-186.

24. Grichnik D, Brinckmann J, Singh L, Manigart S (2014) Beyond environmental scarcity: Human and social capital as driving forces of bootstrapping activities. Journal of Business Venturing 29: 310-326.

25. Chwolka A, Raith MG (2012) The value of business planning before start-up-A decision-theoretical perspective. Journal of Business Venturing 27: 385-399.

26. Pleis LM (2014) A new graduate accounting course for the small business Accountant. Business Education Innovation Journal 6: 70-73.

27. Parker SC, Van Praag CM (2006) The entrepreneur's mode of entry: Business takeover or new venture start? Journal of Business Venturing 27: 31-46.

28. Gupta VK, Turban DB, Pareek A (2013) Differences between men and women in opportunity evaluation as a function of gender stereotypes and stereotype activation. Entrepreneurship Theory and Practice 37: 771-788.

29. Aldrich HE, Yang T (2014) How do entrepreneurs know what to do? Learning and organizing in new ventures. Journal of Evolutionary Economics 24: 59-82.

30. Gupta VK, Goktan AB, Gunay G (2014) Gender differences in evaluation of new business opportunity: A stereotype threat perspective. Journal of Business Venturing 29: 273-288.

31. Bhat VN, Daulerio PP (2014) Paths to entrepreneurial business ownership: U.S. perspective. International Journal of Entrepreneurship and Small Business 21: 527-540.

32. Singer S, Amorós JE, Moska D (2015) Global entrepreneurship monitor 2014 Global Entrepreneurship Research Association, London, UK.

33. Bodlaj M, Rojšek I (2014) Marketing in small firms: The case of Slovenia Economic and Business Review 16: 101-119.

34. Diehl J, Toombs L, Maniam B (2013) Small and medium sized enterprises in the 92 global economy. Journal of American Academy of Business, Cambridge 19: 45-51.

35. Karadag H (2015) Financial management challenges in small and mediumsized enterprises: A strategic management approach. EMAJ: Emerging Markets Journal 5: 26-40.

36. Cruz AD, Howorth C, Hamilton E (2013) Interfamily entrepreneurship: The formation and membership of family entrepreneurial teams. Entrepreneurship Theory and Practice 37: 17-46.

37. Kirkpatrick C (2014) Assessing the impact of regulatory reform in developing countries. Public Administration and Development 34: 162-168.

38. Massenot B, Straub S (2015) Informal sector and economic development: The credit supply channel. Economic Inquiry 54: 10-24.

39. Brannon DL, Wiklund J, Haynie JM (2013) The varying effects of family relationships in entrepreneurial teams. Entrepreneurship Theory and Practice 37: 107-132.

40. Grissemann U, Plank A, Brunner-Sperdin A (2013) Enhancing business performance of hotels: The role of innovation and customer orientation. International Journal of Hospitality Management 33: 347-356.

41. Phillips M, Knowles D (2012) Performance and performativity: Undoing fictions of women business owners. Gender, Work and Organization 19: 416-437.

42. Walker HJ, Bauer TN, Cole MS, Bernerth JB, Feild HS, et al. (2013) Is this how I will be treated? Reducing uncertainty through recruitment interactions. Academy of Management Journal 56: 1325-1347. 